\title{
Magnitude of problem of persons having intellectual disability its impact on parents and their unmet needs in Indian subcontinent
}

\author{
Ranjan Bhattacharyya ${ }^{1}$, Malay Kumar Ghoshal ${ }^{2}$, Debasish Sanyal ${ }^{3}$ \\ ${ }^{1}$ Deptt. of Psychiatry, Murshidabad Medical College \& Hospital, ${ }^{2}$ Deptt. of Psychiatry, Medical College, \\ ${ }^{3}$ Deptt. of Psychiatry, KPC Medical College \& Hospital.
}

\section{ABSTRACT}

\begin{abstract}
Background : Intellectual disability is the clearest example of the mixture of medical and social system models. People with intellectual disability do not represent homogenous groups. Their unmet needs and impact on parents as caregivers also vary especially with changing social milieu, socio economic status and ethnicity. Objectives : To assess the disability of intellectually disabled and the nature and degree of impact on their parents. Methods : The clinico-demographic profile of 102 intellectually disabled and intellectually average children and their caregivers were compared. The impact of disability was measured in NIMH-DIS scale. Results : Mothers experienced more difficulties than fathers in physical care $(\mathrm{p}<0.03)$, health $(\mathrm{p}<0.02)$, career $(p<0.03)$, sibling effect $(p<0.04)$ and specific thoughts domain $(p<0.04)$. Fathers experienced more trouble in support $(\mathrm{p}<0.02)$, financial $(\mathrm{p}<0.05)$, social $(\mathrm{p}<0.01)$, embarrassment/ridicule domains $(\mathrm{p}<0.02)$. There was no difference in Relationship domain $(\mathrm{p}=0.56)$ between the parents. Higher patience $(p<0.02)$ and empathy $(p<0.04)$ were found among mothers and higher tolerance $(p<0.03)$ and sensitivity $(p<0.04)$ were found among mothers. The impact on mothers increased in physical care, health and specific thoughts domains whereas the impact on fathers increased in financial and embarrassment/ridicule domains. Conclusions : Rehabilitation needs increase with severity of disability and impact on parents as caregivers. Appropriate assessment and finding out unmet needs can guide to formulate individualized treatment plan for them as well as for their parents.
\end{abstract}

Key Words : Intellectual disability, parents burden, NIMH DIS scale, rehabilitation needs.

\section{INTRODUCTION}

The term "intellectual disability" is gradually replacing the term "mental retardation" nationwide. In the fifth edition of the Diagnostic and Statistical Manual of Mental Disorders (DSM-5), the APA replaced "mental retardation" with "intellectual disability (intellectual developmental disorder).

Corresponding Author :

Dr Ranjan Bhattacharyya. Assistant Professor \& Head of the Department, Deptt of Psychiatry, Murshidabad Medical College \& Hospital, West Bengal, India. Email : rankholders06@yahoo. co.in/drrbcal@gmail.com
Intellectual disability is the clearest example of the mixture of medical and social system models. Child with disability means a child who deviates from a normal child in mental or physical characteristics to such an extent that he requires special education and related services. People with intellectual disability do not represent homogenous groups. ${ }^{1}$ Their unmet needs and impact on parents as caregivers also vary especially with changing social milieu, socio economic status and ethnicity. Studies have shown that beyond public and self-stigma, stigma can also 
Magnitude of problem of persons having intellectual disability its impact on parents and their unmet needs in Indian subcontinent

impact family members especially the internalised aspects of stigma, known as affiliate stigma, among family caregivers of individuals with disabilities. ${ }^{2}$

As a result of gains in health care, people with intellectual disability are outliving their parents, creating an unprecedented need to support this population. ${ }^{3}$ Siblings represent the longest lasting family relationships and often become caregivers for their brothers and sisters with intellectual disability when parents pass away. ${ }^{4}$ Findings suggest that siblings who have greater access to services and supports experience greater well-being and ability to support their brothers and sisters with intellectual disability. ${ }^{5}$

\section{METHODS}

The clinico-demographic profile of 102 intellectually disabled and their caregivers were compared. The impact of disability was measured in NIMH-DIS scale. FISP-PMR (1998-2003) i) Nature \& degree of impact of parents, ii) Nature \& degree of impacts on family members, iii) Nature \& degree of impact on caregivers other than family members, iv) To identify thrust areas of FISP, v) To objectively evaluate the functioning of FISP. ${ }^{6,7}$

The pilot study on NIMH-DIS scale was conducted on 20 patients by researchers and the inter-rater reliability among two individuals was found to be good $(r=0.849 ; \mathrm{p}<0.00)$. The eleven domains of the scale with maximum scores are as follows: physical care (22), health (16), career (14), support (18), financial (16), social (12), embarrassment/ridicule (14), relationship (18), sibling effect (20), specific thoughts (14), positive impact (18). ${ }^{8,9}$

\section{RESULTS}

The age of 102 parents (51 fathers \& 51 mothers) were as follows : age of father $(38.40 ; 10.28)$ and age of mother (34.22; 8.54) which was not statistically significant. Age of marriage $(p<0.002)$ and age of childbirth $(\mathrm{p}<0.003)$ was found to be statistically significant. Difference in income emerged as one of the demographic variables which was statistically significant $(p<0.048)$. However there was no statistical difference birth order (Table 1).

\section{Table 1 : Demographic Comparisons}

\begin{tabular}{|l|l|l|l|c|c|c|}
\hline \multicolumn{1}{|c|}{$\begin{array}{c}\text { Demographic } \\
\text { Variable }\end{array}$} & Group & N=102 & Mean & SD & F & $\begin{array}{c}\text { Significance } \\
\text { P value }\end{array}$ \\
\hline Age & Father & & & & \\
\hline Age of Marriage & Father & 51 & 34.40 & 10.28 & 1.75 & 0.172 \\
\hline & Mother & 51 & 28.54 & 7.28 & 11.54 & $0.002^{* *}$ \\
\hline Age of Childbirth & Father & 51 & 31.54 & 5.47 & 18.72 & $0.003^{* *}$ \\
\hline & Mother & 51 & 23.36 & 3.28 & & \\
\hline Birth Order & - & - & 2.11 & 1.82 & 3.02 & 0.41 \\
\hline Income & Father & 51 & 3.12 & 1.02 & 3.12 & $0.048^{*}$ \\
\hline & Mother & 51 & 1.21 & 0.86 & & \\
\hline
\end{tabular}


Magnitude of problem of persons having intellectual disability its impact on parents and their unmet needs in Indian subcontinent

Majority of sample belonged to age group 3-6 years $(\mathrm{n}=47 ; 46.8 \%)$ followed by $6-18$ years $(\mathrm{n}=31 ; 30.4 \%)$ and more than 18 years age group $(n=16 ; 15.7 \%)$. Most were having mild intellectual disability and peak incidence was in the age group 3-6 years $(\mathrm{n}=25 ; 55.5 \%)$ (Table 2). There was no statistical difference in the family adjustment and economic adjustment domains in the rural-urban comparisons. However the difference was statistically significant in the Health adjustment $(\mathrm{p}=0.04)$, Social adjustment $(\mathrm{p}=0.02)$ and Parental adjustment $(\mathrm{p}=0.004)$ domains (Table 3).
Mothers experienced more difficulties than fathers in physical care $(23.4 \%$ vs $21.7 \%$; $p<0.03)$, health $(27.9 \%$ vs $19.7 \%$; $\mathrm{p}<0.02)$, career $(28.1 \%$ vs $34.3 \%$; $\mathrm{p}<0.03)$, sibling effect $(24.0 \%$ vs $21.5 \% ; \mathrm{p}<0.04)$ and specific thoughts domain ( $33.4 \%$ vs $30.5 \%$; $<<0.04)$. Fathers experienced more trouble in support $(26.1 \%$ vs $18.6 \%$; $<<0.02)$, financial ( $30.0 \%$ vs $22.8 \%$; $\mathrm{p}<0.03)$, social $(35.3 \%$ vs $25.1 \% ; \mathrm{p}<0.01)$, embarrassment/ ridicule domains $(63.5 \%$ vs $34.3 \% ; \mathrm{p}<0.02)$. There was no difference in Relationship domain $(29.5 \%$ vs $30.1 \% ; \mathrm{p}=0.56$ ) in between the parents.

\section{Table 2 : Age distribution of intellectually disabled children.}

\begin{tabular}{|c|c|c|c|c|}
\hline Age & Mild ID & Moderate ID & Severe ID & Total \\
\hline $0-3 \mathrm{yrs}$ & $3(6.6 \%)$ & $4(9.8 \%)$ & $1(6.7 \%)$ & $8(7.1 \%)$ \\
\hline $3-6 \mathrm{yrs}$ & $25(55.5 \%)$ & $17(41.5 \%)$ & $5(31.1 \%)$ & $47(46.8 \%)$ \\
\hline $6-18 \mathrm{yrs}$ & $12(26.7 \%)$ & $14(34.1 \%)$ & $5(31.1 \%)$ & $31(30.4 \%)$ \\
\hline$>18 \mathrm{yrs}$ & $5(11.2 \%)$ & $6(14.6 \%)$ & $5(31.1 \%)$ & $16(15.7 \%)$ \\
\hline
\end{tabular}

\section{Table 3 : Rural-Urban comparison of parents with intellectually disabled children (Modified adjustment inventory)}

\begin{tabular}{|l|l|c|c|c|c|c|}
\hline \multicolumn{1}{|c|}{ Variables } & Groups & N=102 & Mean & SD & $\begin{array}{c}\text { Students } \\
\mathbf{t} \text { test }\end{array}$ & p \\
\hline $\begin{array}{l}\text { Family } \\
\text { adjustment }\end{array}$ & Rural & 68 & 58.44 & 10.52 & -1.014 & 0.64 \\
\cline { 2 - 7 } & Urban & 34 & 31.65 & 7.12 & & \\
\hline \multirow{2}{*}{$\begin{array}{l}\text { Emotional } \\
\text { adjustment }\end{array}$} & Rural & 68 & 59.21 & 9.59 & 1.006 & 0.38 \\
\cline { 2 - 7 } & Urban & 34 & 29.81 & 6.24 & & \\
\hline \multirow{2}{*}{$\begin{array}{l}\text { Health } \\
\text { adjustment }\end{array}$} & Rural & 68 & 57.12 & 12.42 & -1.842 & $0.04^{*}$ \\
\cline { 2 - 7 } Social adjustment & Urban & 34 & 28.24 & 9.78 & 2.141 & $0.02^{*}$ \\
\cline { 2 - 8 } & Rural & 68 & 54.82 & 14.74 & & \\
\hline \multirow{2}{*}{$\begin{array}{l}\text { Parental } \\
\text { adjustment }\end{array}$} & Urban & 34 & 24.72 & 12.71 & & \\
\cline { 2 - 8 } & Urban & 34 & 52.78 & 18.76 & & \\
\hline
\end{tabular}


Magnitude of problem of persons having intellectual disability its impact on parents and their unmet needs in Indian subcontinent

Higher patience $(\mathrm{p}<0.02)$ and empathy $(\mathrm{p}<0.04)$ among mothers and higher tolerance $(\mathrm{p}<0.03)$ and sensitivity $(p<0.04)$ was found among fathers. The impact on mother increased in physical care, health and specific thoughts domains whereas the impact on father increased in financial and embarrassment/ ridicule domains in successive assessments (Table 4).

\section{Table 4 : Domain wise scoring of NIMH-DIS scale in parents of intellectually disabled children}

\begin{tabular}{|c|c|c|c|c|c|c|}
\hline \multirow{3}{*}{$\begin{array}{r}\text { Areas } \\
\text { Physical care }\end{array}$} & \multirow{3}{*}{$\begin{array}{c}\text { Maximum } \\
\text { score } \\
1430\end{array}$} & \multirow{3}{*}{$\begin{array}{c}\text { Obtained Score } \\
\begin{array}{c}\text { Father } \\
\text { Mother }\end{array} \\
310\end{array}$} & \multicolumn{4}{|c|}{ Percentage (\%) } \\
\hline & & & \multicolumn{2}{|c|}{ Father } & \multirow{2}{*}{$\begin{array}{l}\text { Mother } \\
23.4 \%\end{array}$} & \multirow{2}{*}{$\begin{array}{c}\text { P value } \\
0.03\end{array}$} \\
\hline & & & 334 & $21.7 \%$ & & \\
\hline Health & 1040 & 205 & 291 & $19.7 \%$ & $27.9 \%$ & 0.02 \\
\hline Career & 910 & 256 & 312 & $28.1 \%$ & $34.3 \%$ & 0.03 \\
\hline Support & 1170 & 305 & 218 & $26.1 \%$ & $18.6 \%$ & 0.02 \\
\hline Financial & 1040 & 312 & 237 & $30.0 \%$ & $22.8 \%$ & 0.03 \\
\hline Social & 780 & 275 & 196 & $35.3 \%$ & $25.1 \%$ & 0.01 \\
\hline Embarrassment/Ridicule & 910 & 312 & 198 & $34.3 \%$ & $63.5 \%$ & 0.02 \\
\hline Relationship & 1170 & 345 & 352 & $29.5 \%$ & $30.1 \%$ & 0.56 \\
\hline Sibling effect & 1300 & 279 & 312 & $21.5 \%$ & $24.0 \%$ & 0.04 \\
\hline Specific thoughts & 910 & 278 & 304 & $30.5 \%$ & $33.4 \%$ & 0.04 \\
\hline Total negative thoughts & 10660 & 2877 & 2754 & $26.9 \%$ & $25.8 \%$ & 0.65 \\
\hline Positive impact & 1170 & 534 & 532 & $45.6 \%$ & $45.5 \%$ & 0.57 \\
\hline
\end{tabular}

\section{DISCUSSIONS}

The parents of intellectually disabled children experienced more positive impact than negative impact due to changes in life style, standard of living, changes \& means of recreation \& leisure activities and perception of family members towards disabled child..$^{10}$

Positive impact inversely correlated to behavioural problems. ${ }^{11}$ Latino mothers score better than Anglo mothers in respect to positive impact on children having ID. Indian mothers score more in positive impact $(55.38 \%)$ than negative impact $(26.26 \%)$. Mothers spent more time, offered more types of support \& perceived more caregivers burden. ${ }^{12,13}$ Parents usually take pride in their children's achievements but are easily hurt by their children's failures.

The challenges faced by aging parents of adults with mental disability are plenty. External service agencies that aim to cater to the needs of persons with mental disability only, don't serve the purpose. Services that pay equal attention to the needs of the parents are essential. Social Workers and other professionals, while considering the well-being of the disabled, need to consider the well-being of the parents of disabled too.

Two changes have made enormous impact in caregiving for intellectual disabled. They are increased longevity and paradigm shift from 
Magnitude of problem of persons having intellectual disability its impact on parents and their unmet needs in Indian subcontinent

institutional caregiving to home caregiving. ${ }^{14,15}$ The core themes of positive impact are source \& joy of happiness, increased sense of purpose, expanded social\& personalnetworks, community involvement, increased spirituality, source of family unity \& closeness, increased tolerance \& understanding., personal growth \& strength and positive impact on others/community. ${ }^{16,17,18}$

\section{SUMMARY \& CONCLUSIONS}

The rehabilitation needs increase with severity of disability and impact on parents as caregivers. Appropriateassessmentand finding out unmetneeds can guide to formulate individualized treatment plan for them as well as to their parents. The implications of present study is that by assessment of burden with available social support, appropriate strategy and intervention can be formulated which will help in counselling the parents and thus will reduce the burden of caregivers of intellectually disabled children. 19 This will help the parents to accept children as they are. They may not unnecessarily reject, punish, and show hostility towards their children. Majority of studies on parenting stress and family burden associated with raising a disabled child have focused on mothers.

Mothers face more stress as compared to fathers because mothers bear disproportionate share of responsibilities in raising their disabled child. Parenting with intellectually disabled children is not an easy job. Parents or other caregivers can be affected by many ways by having children with intellectual disability. ${ }^{20}$

The challenges faced by aging parents of adults with mental disability are plenty. External service agencies that aim to cater to the needs of persons with mental disability only, don't serve the purpose. Services that pay equal attention to the needs of the parents are essential. Social Workers and other professionals, while considering the well-being of the disabled, need to consider the well-being of the parents of disabled too. ${ }^{21}$

The skills training to the caregivers can help them to deal effectively with the person with ID. It will also help to improve the quality of life, and take positive steps to handle the children more constructively. The limitations of present study are first only modest sample size $(n=102)$. Majority of sample are from the urban background. A longitudinal study with more subjects is required to corroborate the findings of the present study.

Despite these shortcomings present study explores new dimensions in parental burden with caregiving for children having intellectual disability. A community based study is required with liasion between interdisciplinary team (Psychiatrists, Paediatrician etc) with other mental health care professionals (Clinical psychologist, Special educator, Speech \& language therapists etc) which could be a cost-effective measure.

\section{Conflicts of interest : none}

\section{REFERENCES}

1. Abbott, D., Meredith, W. Strengths of parents with retarded children. Family Relations, 1986; 35; 371-373.

2. Bebko, J., Konstantareas, M., Springer, J. Parent and professional evaluations of family stress associated with characteristics of autism. Journal of Autism and Develop Disorders 1987, 17 : 565-576.

3. Beavers J., Hampson R. B., Hulgus Y F, Beavers, WR. Coping in families with a retarded child. Family Process $1986 ; 25: 365-78$

4. Blanker J, Baker. BL, Maclean. WE. Positive Impact of Intellectual Disability on Families. American Journal on Mental Retardation 2007; $11: 330-48$

5. Gary DE, Holden WJ. Psychosocial wellbeing among the parents of children with autism. Journal of Intellectual Developmental Disabilities 1992; 1 : 83-93.

6. Girimaji SC, Shobha. S. etal. Family interview for stress and coping in mental retardation (FISC-MR). Indian Journal of Psychiatry 1999; $41: 341-49$.

7. Heller T, Hsieh K., Rowitz, L. Maternal and Paternal care giving of persons with mental retardation across the life span. Family relations, 1997; $46:$ 407-15.

8. Peshwaria R., etal. Parent involvement in the training and management of their mentally handicapped persons. Journal of Personality \& Clinical Studies 1995; 5 : 217-21.

9. Peshawaria R, Menon DK., Bailey D. NIMH Disability Impact Scale. Secunderabad, India : 2000. National Institute of Mentally Handicapped.

10. Stainton T., Besser H. (1992). The positive impact of children with an intellectual disability on the family. Journal of Intellectual and Developmental D. 


\section{Magnitude of problem of persons having intellectual disability its impact on parents and their unmet needs in Indian subcontinent}

11. Blacher, J., Baker, B.. L. \& Kaladjian, A. (in press). Positive and negative parenting of preschool children with and without ID : Syndrome and observation context. Journal of Autism and Developmental Disorders.

12. Heller T, Roccoforte, J.A., Hsieh K., etal. Benefits of support groups for families of adults with severe mental illness. American Journal of Orthopsychiatry 1997; 67 : 187-98.

13. Blacher J., Begum, G.F., Marcoulides, G. A., \& Baker, B. L. (in press). Longitudinal perspectives of child positive impact on families : Relationship to disability and culture. American Journal of Intellectual and Developmental Disabilities.

14. Jin YS. Social support for families of children with mental retardation: Comparison between Korea and the US. Journal of Mental Retardation 2001; $40: 103-18$.

15. Kazak AE, Marvin RS. Stress and social networks in families with a handicapped child. Family Relation 1985; 33 : 66-7.

16. Kearney PM, Griffin T. Between joy and sorrow. Being a parent of a child with developmental disability. Journal of Advanced Nursing, 2001; $34: 582-92$.
13. Kishore MT. Disability impact and coping in mothers of children with intellectual disabilities and multiple disabilities. Journal of intellectual disabilities 2011; $15: 4241-51$.

14. Pearson JE. etal. A mutual help project for families of handicapped children. Journal of Counseling and Development 1986; 65 : 2 13-15.

15. Singh TK., Indla V., Indla RR., etal. Impact of disability of mentally retarded persons on their parents. Indian Journal of Psychology 2008; 30.

20. Werner S, Shulman C. Does type of disability make a difference in affiliate stigma among family caregivers of individuals with autism, intellectual disability or physical disability? Journal of Intellectual Disability Research 2015; 59 : 272-283.

21. Holl E, Morano CL. Supporting the Next Generation of Caregivers : Service Use and Needs of Adult Siblings of Individuals with Intellectual Disability. Inclusion : 2014; 2, 2-1. 